\title{
Mesoporous silica nanoparticles functionalised with a photoactive ruthenium(II) complex: Exploring the formulation of a metal-based photodynamic therapy photosensitiser
}

\author{
Younes Ellahioui ${ }^{1}$, Malay Patra ${ }^{2}$, Cristina Mari ${ }^{2}$, Rim Kaabi ${ }^{1}$, Johannes Karges ${ }^{3}$, Gilles \\ Gasser ${ }^{3, *}$ and Santiago Gómez-Ruiz ${ }^{1, *}$ \\ 1 Departamento de Biología y Geología, Física y Química Inorgánica, ESCET, Universidad Rey Juan \\ Carlos, Calle Tulipán s/n, E-28933, Móstoles (Madrid), Spain; santiago.gomez@uric.es \\ 2 Department of Chemistry, University of Zurich, Winterthurerstrasse 190, CH-8057 Zurich, Switzerland \\ 3 Chimie ParisTech, PSL University, Laboratory for Inorganic Chemical Biology, F-75005 Paris, France; \\ gilles.gasser@chimieparistech.psl.eu
}
* Correspondence: santiago.gomez@uric.es (https://santiago-gomez-ruiz.webnode.es/comet-nano- group/); gilles.gasser@chimieparistech.psl.eu (www.gassergroup.com).

\begin{abstract}
A series of nanomaterials based on mesoporous silica have been synthesised and functionalised with a photoactive polypyridyl ruthenium(II) complex, namely [Ru(bipy) ${ }_{2}$-dppz-7hydroxymethyl] $\left[\mathrm{PF}_{6}\right]_{2}$ (bipy = 2,2'-bipyridine, dppz = dipyrido[3,2-a:2',3'-c]phenazine) by various methods. The functionalisation reactions were based on the covalent binding to different ligands attached to the pores of the mesoporous nanoparticles and a simple physisorption using polyamino-functionalised mesoporous silica nanoparticles. The resulting nanostructured systems have been characterised by XRD, XRF, BET, SEM and TEM, observing the incorporation of the metallodrug onto the nanostructured silica in a different way depending on the synthetic method used in the loading reactions. In our studies, we have also observed that functionalisation with the metallodrug causes changes in the structural and textural features of the materials. The phototherapeutic activity of the ruthenium-functionalised materials in HeLa cervical cancer cells have been tested and the preliminary results are presented herein.
\end{abstract}

Keywords: cytotoxicity; mesoporous silica nanoparticles; photodynamic therapy; ruthenium.

Abbreviations: $\mathrm{BET}=$ Brunauer, Emmett and Teller; bipy $=2$ 2, '-bipyridine; $\mathrm{BJH}=$ Barrett, Joyner and Halenda; $\mathrm{CP}=$ cross polarization; $\mathrm{CTAB}=$ cetyltrimethylammonium bromide; DMEM = Dulbecco's Modified Eagle's medium; dppz = dipyrido[3,2-a:2',3'-c]phenazine; DR-UV $=$ diffuse reflectance Ultraviolet spectroscopy; EPR $=$ enhanced permeability and retention effect; FBS = Foetal Bovine Serum; FT-IR = Fourier Transformed Infrared spectroscopy; ICP$M S=$ Inductively coupled plasma mass spectrometry; MAS = magic angle spinning; MDR = multidrug resistance; $\mathrm{MSN}=$ mesoporous silica nanoparticles; $\mathrm{PDT}=$ photodynamic therapy; SEM = Scanning Electron Microscopy; TEM = Transmission Electron Microscopy; TEOS = tetraethylorthosilicate; $\mathrm{XRD}=\mathrm{X}$-ray diffraction; $\mathrm{XRF}=\mathrm{X}$-ray fluorescence. 


\section{Introduction}

The use of metallodrugs to treat cancer was greatly developed after the serendipitous discovery of cisplatin (cis-diamminodichloroplatinum(II)) by the research team of Rosenberg in the late 1960's. ${ }^{1}$ Since then, metal-based drugs have been investigated for different medicinal or diagnostic applications against various cancer-related issues. ${ }^{2,3}$ However, the full exploitation of the specific physicochemical properties of metallodrugs has been, and is still, hampered by the fact that some of the most interesting synthesised agents present severe side effects, ${ }^{4}$ are becoming less active or even inactive after several treatments due to the development of resistance ${ }^{5}$ and, usually, possess low stability in aqueous solutions, ${ }^{6}$ precluding their administration to humans. Nevertheless, the associated problems to the use of metal-based drugs in cancer treatment or for diagnosis, have also boosted the search for novel alternatives using different metals and ligands with improved properties against cancer, especially when speaking about the development of multidrug resistance (MDR) ${ }^{7,8}$

When one thinks about the use and application of metallodrugs in humans, many questions arise regarding their stability, transport to cell, membrane crossing, targeting and some other processes which usually lead to the transformation of the metallodrug to give the final active species which interacts with the biological target(s). ${ }^{9}$ Therefore, the administration of metallodrugs is a very important issue that needs to be addressed to minimise the speciation reactions.

In this context, in recent years, several approaches based on different nanostructured materials as vectors for metallodrugs have been used for protecting and subsequently delivering the metal-containing active species to the biological target(s). ${ }^{10,11}$ Thus, many different nanosystems have been tested in vitro and in vivo ${ }^{10}$ with a very extensive study of nanostructured mesoporous silica loaded with titanocene derivatives. ${ }^{11-20}$ organotin compounds $\mathrm{s}^{20-22}$ or other metallodrugs. ${ }^{10,23}$. This approach has been shown to be highly effective against cancer cell lines. ${ }^{10,11}$

At our end, in most of our studies, we have observed that metallodrug-functionalised silicabased nanomaterials usually work as "non-classical" drug-delivery nanosystems because they do not release the metal-based drug, but, in most of the cases, they act as an entire nanoparticulated therapeutic system, presumably by the action of the metallodrug supported onto the silica particles. These systems base their improved cytotoxic action on a higher cell uptake of metal-containing active species of metallodrug-functionalised silica-based systems, compared to "free" metallodrugs, because of a high uptake of silica particles by the cancer cells due to the enhanced permeability and retention (EPR) effect of malignant cells. In addition, the support of the metallodrugs onto different nanostructured systems usually leads to a different mechanism of cytotoxic action compared with that of non-encapsulated "free" metallodrugs ${ }^{10,11}$. In brief, the dynamics of apoptotic morphological and functional changes is modified when the metallodrug are incorporated into nanostructured silica-based systems. ${ }^{16,18}$

All our studies have been carried out using cytotoxic titanium- or tin-based metallodrugs and have been focused on the potential use of these nanostructured systems in chemotherapy, however, we decided to expand to other metal complexes with improved therapeutic properties. We therefore became interested in ruthenium complexes as their photoactivation is of great interest nowadays because of their potential therapeutic mild processes against cancer. ${ }^{24-29}$ Thus, a wide variety of dual photoreleasing and photoactive systems have been studied and have been considered as interesting alternatives to current treatments. ${ }^{30-33}$ Lately, several photoactivatable $\mathrm{Ru}(\mathrm{II})$ complexes with interesting biological properties have been published. ${ }^{25,34-40}$ As a highlight, one of such compounds, namely TLD-1433 from the McFarland group, has now entered clinical trial as a PDT photosensitiser to treat bladder cancer ${ }^{41}$. However, to the best of our knowledge, there are only a few reports on the use of ruthenium compounds with therapeutic properties supported onto mesoporous silica, ${ }^{42,43}$ which have been synthesised using a very similar approach to the one that we published in $2009^{10,12}$ and have been tested in terms of regular cytotoxicity. Additionally, some other more advanced cytotoxic systems based on silica have also been reported. ${ }^{44-46}$ Only very recently, a Ru(II) complex was 
covalently bound to mesoporous silica nanoparticles (MSN) for a subsequent cellular uptake of the particles and release of the ruthenium complexes to be transformed upon light irradiation into a cytotoxic complex ${ }^{47}$ and a similar approach has been studied using other ruthenium complexes ${ }^{48}$ or silicon nanoparticles. ${ }^{49}$ or other non-polymeric nanoparticles. ${ }^{50}$

In this context and in view of the low number of examples of ruthenium-functionalised silica-based materials with phototherapeutic properties, we decided to combine the experience of our groups on the synthesis, characterization and phototherapeutic studies of ruthenium complexes ${ }^{51-53}$ with our knowledge on the field of metallodrug-functionalised nanostructured materials, ${ }^{11-22}$ preparing a series of MSN functionalised with a photoactive compound using different synthetic protocols. All the materials have been characterised by different methods and a preliminary study of the potential biological application of the materials in photodynamic therapy is described.

\section{Materials and Methods}

\subsection{General conditions}

All the functionalisation reactions were performed using standard Schlenk tube techniques in an atmosphere of dry nitrogen. Solvents were distilled from the appropriate drying agents and degassed before use. The reagents used in the preparation of the ruthenium derivative were purchased from Sigma Aldrich and used directly without further purification. 3chloropropyltriethoxysilane, 3-isocyanatopropyltriethoxysilane and tris(2-aminoethyl)amine, TEOS, $\mathrm{NaOH}$ and CTAB were purchased from Sigma Aldrich and used directly without further purification. The ruthenium complex, $\left[R u(\text { bipy })_{2}\right.$-dppz-7-hydroxymethyl] $\left[\mathrm{PF}_{6}\right]_{2}$ (bipy $=2,2$ 'bipyridine, dppz $=$ dipyrido[3,2-a:2',3'-c]phenazine, was prepared according to the literature procedure reported by us. ${ }^{35}$

\subsection{General conditions on the characterization of the materials}

${ }^{1} \mathrm{H},{ }^{13} \mathrm{C}-\mathrm{CP}$ MAS and ${ }^{29} \mathrm{Si}$ MAS NMR spectra and ${ }^{31} \mathrm{P}$ NMR were recorded on a VarianInfinity Plus Spectrometer at $400 \mathrm{MHz}$ operating at $100.52 \mathrm{MHz}$ proton frequency (4 $\mu \mathrm{s} 90^{\circ}$ pulse, 4000 transients, spinning speed of $6 \mathrm{MHz}$, contact time $3 \mathrm{~ms}$, pulse delay $1.5 \mathrm{~s}$ ). X-ray diffraction (XRD) pattern of the silicas were obtained on a Philips Diffractometer model PW3040/00 X'Pert MPD/MRD at $45 \mathrm{KV}$ and $40 \mathrm{~mA}$, using a wavelength $\mathrm{Cu} \mathrm{Ka}(\lambda=1.5418 \AA)$. $\mathrm{Ru}$ wt \% determination by $\mathrm{X}$-ray fluorescence was carried out with an $\mathrm{X}$-ray fluorescence spectrophotometer Philips MagiX with a X-ray source of $1 \mathrm{~kW}$ and a Rh anode using a helium atmosphere. The quantification method is able to analyse from $0.0001 \%$ to $100 \%$ ruthenium. $N_{2}$ gas adsorption-desorption isotherms were performed using a Micromeritics ASAP 2020 analyser. Scanning electron micrographs and morphological analysis were carried out on a XL30 ESEM Philips with an energy dispersive spectrometry system (EDS). The samples were treated with a sputtering method with the following parameters: Sputter time $100 \mathrm{~s}$, Sputter current $30 \mathrm{~mA}$, film thickness $20 \mathrm{~nm}$ using a Sputter coater BAL-TEC SCD 005. Conventional transmission electron microscopy (TEM) was carried out on a TECNAI 20 Philips, operating at $200 \mathrm{kV}$.

\subsection{Synthesis of mesoporous silica nanoparticle (MSN)}

The mesoporous silica nanoparticles (MSNs) were synthesised with slight modifications of the method described by Zhao et al.. ${ }^{54}$ In brief, hexadecyltrimethylammonium bromide (CTAB, $2.00 \mathrm{~g}, 5.48 \mathrm{mmol}$ ) was added to $960 \mathrm{~mL}$ of nanopure water, and subsequently $7 \mathrm{~mL}$ of $2.00 \mathrm{M}$ sodium hydroxide aqueous solution were added and the mixture stirred at $80 \stackrel{\circ}{\circ}$. Subsequently, tetraethylorthosilicate (TEOS, $10 \mathrm{~mL}, 45 \mathrm{mmol}$ ) was added dropwise to the surfactant solution under vigorous stirring. The mixture was then stirred for $2 \mathrm{~h}$ to give a white precipitate. The resulting product was isolated by filtration, washed with nanopure water and methanol and dried 
under vacuum overnight. The surfactant template (CTAB) was removed after calcination at 550 $\stackrel{\circ}{ } \mathrm{C}$ for $12 \mathrm{~h}$. 


\subsection{Synthesis Cl-functionalized MSN (MSN-CL)}

A solution of 3-chloropropyltriethoxysilane $(5.80 \mathrm{~mL}, 22.6 \mathrm{mmol})$ in toluene $(100 \mathrm{~mL})$ was added to dehydrated MSN $(5.00 \mathrm{~g})$ and the mixture was stirred $48 \mathrm{~h}$ at $110 \stackrel{\circ}{\circ}$. The slurry was filtered through fritted discs and the solid residue washed with toluene $(5 \times 200 \mathrm{~mL})$ and diethylether $(5 \times 200 \mathrm{~mL})$. The resultant solid was dried under vacuum at room temperature for $24 \mathrm{~h}$ to give a white free flowing powder.

\subsection{Synthesis of CNO-functionalized MSN (MSN-CNO)}

A solution of 3-isocyanatopropyltriethoxysilane $(1.00 \mathrm{~g})$ in toluene $(30 \mathrm{~mL})$ was added to dehydrated MSN $(1.00 \mathrm{~g})$ and the mixture was stirred $48 \mathrm{~h}$ at $110{ }^{\circ} \mathrm{C}$. The slurry was filtered through fritted discs and the solid residue washed with toluene $(5 \times 50 \mathrm{~mL})$ and diethylether $(5 \times$ $50 \mathrm{~mL}$ ). The resultant solid was dried under vacuum at room temperature for $24 \mathrm{~h}$ to give a white free flowing powder (MSN-CNO).

\subsection{Synthesis of triamine-functionalized MSN (MSN-TRI)}

A solution of tris(2-aminoethyl)amine (TRI $2.40 \mathrm{~mL}, 16.0 \mathrm{mmol}$ ) in toluene $(50 \mathrm{~mL})$ was added to a suspension of MSN-CL $(1.00 \mathrm{~g})$ in toluene $(50 \mathrm{~mL})$ and the mixture was stirred for $48 \mathrm{~h}$ at $110 \stackrel{\circ}{\circ} \mathrm{C}$. The slurry was filtered through fritted discs and the solid residue was washed with toluene $(5 \times 200 \mathrm{~mL})$, ethanol $(5 \times 200 \mathrm{~mL})$, methanol $(5 \times 200 \mathrm{~mL})$ and diethylether $(5 \times$ $200 \mathrm{~mL}$ ). The resultant solid was dried under vacuum at room temperature for $24 \mathrm{~h}$ giving a white free flowing powder (MSN-TRI)

\subsection{Synthesis of MSN-CL-Ru}

A suspension of $\left[\mathrm{Ru}(\mathrm{bipy})_{2}\right.$-dppz-7-hydroxymethyl] $\left[\mathrm{PF}_{6}\right]_{2}(10 \mathrm{mg})$ (to obtain a theoretical level of $5 \%$ ruthenium/MSN) in ethanol $(100 \mathrm{~mL})$ was added to $\mathbf{M S N}(190 \mathrm{mg})$ and the mixture was stirred at room temperature for 10 minutes, subsequently an excess of the stoichiometric amount of trimethylamine (1.5:1 with $\left[\mathrm{Ru}(\text { bipy })_{2}\right.$-dppz-7-hydroxymethyl] $\left.\left[\mathrm{PF}_{6}\right]_{2}\right)$ was added to the mixture which was then stirred under reflux during $48 \mathrm{~h}$. The slurry was filtered through fritted discs and the solid residue was washed several times with ethanol $(5 \times 200 \mathrm{~mL})$ water $(5 \times 200$ $\mathrm{mL})$ and diethylether $(5 \times 200 \mathrm{~mL})$ and then dried under vacuum at room temperature for $24 \mathrm{~h}$ to give a pale orange free flowing powder (MSN-CL-Ru)

\subsection{Synthesis of MSN-CNO-Ru}

A suspension of $\left[\mathrm{Ru}\left(\right.\right.$ bipy) ${ }_{2}$-dppz-7-hydroxymethyl] $\left[\mathrm{PF}_{6}\right]_{2}(10 \mathrm{mg})$ (to obtain a theoretical level of $5 \%$ Ru/MSN-CNO) in ethanol $(100 \mathrm{~mL}$ ) was added to MSN-CNO (190 mg) and the mixture was stirred at room temperature for 10 minutes, subsequently an excess of the stoichiometric amount of pyridine (1.5:1 molar ratio with [Ru(bipy) ${ }_{2}$-dppz-7hydroxymethyl] $\left[\mathrm{PF}_{6}\right]_{2}$ ) was added to the mixture which was then stirred under reflux during $48 \mathrm{~h}$. The slurry was filtered through fritted discs and the solid residue was washed several times with ethanol $(5 \times 100 \mathrm{~mL})$ water $(5 \times 100 \mathrm{~mL})$ and diethylether $(5 \times 100 \mathrm{~mL})$ and then dried under vacuum at room temperature for $24 \mathrm{~h}$ to give a pale orange free flowing powder.

\subsection{Synthesis of MSN-TRI-Ru}

A suspension of $\left[\mathrm{Ru}(\mathrm{bipy})_{2}\right.$-dppz-7-hydroxymethyl] $\left[\mathrm{PF}_{6}\right]_{2}(48 \mathrm{mg})$ (to obtain a theoretical level of $20 \% \mathrm{Ru} / \mathrm{MSN}-\mathrm{TRI}-\mathrm{NH}$ ) in ethanol $(100 \mathrm{~mL}$ ) was added to MSN-TRI-NH (190 mg, respectively) and the mixture was stirred at room temperature for 10 minutes and then stirred under reflux during $48 \mathrm{~h}$. The slurry was filtered through fritted discs and the solid dried under vacuum at room temperature for $24 \mathrm{~h}$ to give an orange free flowing powder. 


\subsection{Biological studies: cell culture conditions, Cytotoxicity and phototoxicity assays.}

HeLa (human cervical cancer) cells were grown in DMEM (Gibco) medium supplemented with $10 \%$ fetal bovine serum (FBS, Gibco) and 1\% penicillin/streptomycin. Cells were cultured at 37 $\square \mathrm{C}$ in a humidified atmosphere containing $5 \% \mathrm{CO}_{2}$.

The cytotoxicity of the ruthenium complex and its three MSN conjugates against HeLa cells in the presence and absence of UV irradiation was measured using a resazurin (Promocell $\mathrm{GmbH}$ ) based fluorometric cell viability assay. In 96-well plates, cells (at a density of $4 \times 10^{3}$ cells per well) were seeded in triplicate in $100 \mu \mathrm{L}$ medium $24 \mathrm{~h}$ prior to treatment. The following day, cells were treated with increasing concentrations of compounds. For this purpose, freshly prepared stocks (note: due to their insolubility in aqueous media, MSN and ruthenium-MSN conjugates are added as suspension) were diluted using the respective cell culture media and $100 \mu \mathrm{L}$ was added to each well (total volume $200 \mu \mathrm{L} /$ well). For evaluation of cytotoxicity, cells were incubated with compounds for $48 \mathrm{~h}$ before the medium was replaced by $100 \mu \mathrm{L}$ complete medium containing resazurin $(0.2 \mathrm{mg} / \mathrm{mL})$. After $4 \mathrm{~h}$ of incubation, fluorescence of the highly fluorescent resorufin metabolite at $580 \mathrm{~nm}$ emission was quantified using a SpectraMax M5 microplate reader with an excitation wavelength of $540 \mathrm{~nm}$.

To assess phototoxicity, cells were treated with increasing concentrations of compounds for $4 \mathrm{~h}$ only. After that, the medium was removed and replaced by fresh complete medium and either kept in the dark or irradiated for $10 \mathrm{~min}$ with $350 \mathrm{~nm}$ UVA $\left(2.58 \mathrm{Jcm}^{-2}\right)$. Cells were then returned to the incubator for an additional $44 \mathrm{~h}$. After incubation, the viability was quantified using the resazurin assay as described above. The resorufin fluorescence intensities were normalized to untreated control wells and plotted as concentration of test compound versus \% cell viability. $\mathrm{IC}_{50}$ values were interpolated from the resulting dose-dependence curves. The reported $\mathrm{IC}_{50}$ values are the average from at least three independent experiments.

\subsection{Photophysical studies: emission, luminescence quantum yield, lifetimes}

For the determination of the emission and luminescence quantum yields $\left(\Phi_{\text {em }}\right)$, the samples were prepared in an $\mathrm{CH}_{3} \mathrm{CN}$ solution with an absorbance of 0.1 at $355 \mathrm{~nm}$. This solution was irradiated in fluorescence quartz cuvettes (width $1 \mathrm{~cm}$ ) using a NT342B OPO pulse laser NdYAG pumped optical parametric oscillator (Ekspla) at $355 \mathrm{~nm}$. The emission signal was focused and collected at right angle to the excitation pathway and directed to a Princeton Instruments Acton SP-2300i monochromator equipped with $1200 \mathrm{~g} / \mathrm{mm}$ grating blazed at $500 \mathrm{~nm}$. As a detector a XPI-Max 4 CCD camera (Princeton Instruments) has been used. The luminescence quantum yields were determined by comparison with the reference $\left[\mathrm{Ru}(\mathrm{bipy})_{3}\right] \mathrm{Cl}_{2}$ in $\mathrm{CH}_{3} \mathrm{CN}$ $\left(\Phi_{\mathrm{em}}=5.9 \%\right)^{55}$ applying the following formula:

$$
\begin{gathered}
\Phi_{\text {em }, \text { sample }}=\Phi_{\text {em,reference }} * \frac{F_{\text {reference }}}{\mathrm{F}_{\text {sample }}} * \frac{\mathrm{I}_{\text {sample }}}{I_{\text {reference }}} *\left(\frac{\mathrm{n}_{\text {sample }}}{\mathrm{n}_{\text {reference }}}\right)^{2} \\
\mathrm{~F}=1-10^{-A}
\end{gathered}
$$

$\Phi_{\mathrm{em}}=$ luminescence quantum yield, $\mathrm{F}=$ fraction of light absorbed, $\mathrm{I}=$ integrated emission intensities, $n=$ refractive index, $A=$ absorbance of the sample at irradiation wavelength

For the determination of the lifetimes, the samples were prepared in an air saturated and in a degassed $\mathrm{CH}_{3} \mathrm{CN}$ solution with an absorbance of 0.1 at $355 \mathrm{~nm}$. This solution was irradiated in fluorescence quartz cuvettes (width $1 \mathrm{~cm}$ ) using a NT342B Nd-YAG pumped optical parametric oscillator (Ekspla) at $355 \mathrm{~nm}$. The emission signal was focused and collected at right angle to the excitation pathway and directed to a Princeton Instruments Acton SP-2300i monochromator equipped with $1200 \mathrm{~g} / \mathrm{mm}$ grating blazed at $500 \mathrm{~nm}$. As a detector a R928 photomultiplier tube (Hamamatsu) has been used.

\subsection{Photophysical studies: Singlet oxygen measurement}

The singlet oxygen production of a sample has been determined by two methods (direct and indirect) as already descibed in previous publications of our group. ${ }^{35,51,53,56}$

- Direct evaluation 
The samples were prepared in an air saturated $\mathrm{CH}_{3} \mathrm{CN}$ or $\mathrm{D}_{2} \mathrm{O}$ solution with an absorbance of 0.2 at $450 \mathrm{~nm}$. This solution was irradiated in fluorescence quartz cuvettes (width $1 \mathrm{~cm}$ ) using a mounted M450LP1 LED (Thorlabs) whose irradiation, centred at $450 \mathrm{~nm}$, has been focused with aspheric condenser lenses. The intensity of the irradiation has been varied using a T-Cube LED Driver (Thorlabs) and measured with an optical power and energy meter. The emission signal was focused and collected at right angle to the excitation pathway and directed to a Princeton Instruments Acton SP-2300i monochromator equipped with $600 \mathrm{~g} / \mathrm{mm}$ grating blazed at 1200 $\mathrm{nm}$. A longpass glass filter was placed in front of the monochromator entrance slit to cut off light at wavelengths shorter than $850 \mathrm{~nm}$. The slits for detection were fully open. As a detector an EO-817L IR-sensitive liquid nitrogen cooled germanium diode detector (North Coast Scientific Corp.) has been used. The singlet oxygen luminescence at $1270 \mathrm{~nm}$ was measured by recording spectra from 1100 to $1400 \mathrm{~nm}$. For the data analysis, the singlet oxygen luminescence peaks at different irradiation intensities were integrated. The resulting areas were plotted against the percentage of the irradiation intensity and the slope of the linear regression calculated. The absorbance of the sample was corrected with an absorbance correction factor. As reference for the measurement in an $\mathrm{CH}_{3} \mathrm{CN}$ solution phenalenone ( phenaleone $\left.=95 \%\right)^{57}$ and for the measurement in a $\mathrm{D}_{2} \mathrm{O}$ solution $\left[\mathrm{Ru}(\mathrm{bipy})_{3}\right] \mathrm{Cl}_{2}\left(\Phi \mathrm{Ru}(\mathrm{bipy})_{3} \mathrm{Cl}_{2}=22 \%\right)^{58}$ was used and the singlet oxygen quantum yields were calculated using the following formula:

$$
\begin{gathered}
\Phi_{\text {sample }}=\Phi_{\text {reference }} * \frac{\mathrm{S}_{\text {sample }}}{S_{\text {reference }}} * \frac{I_{\text {reference }}}{I_{\text {sample }}} \\
I=I_{0} *\left(1-10^{-A}\right)
\end{gathered}
$$

$\Phi=$ singlet oxygen quantum yield, $S=$ slope of the linear regression of the plot of the areas of the singlet oxygen luminescence peaks against the irradiation intensity, $I=$ absorbance correction factor, $\mathrm{I}_{0}=$ light intensity of the irradiation source, $\mathrm{A}=$ absorbance of the sample at irradiation wavelength.

\section{- Indirect evaluation}

For the measurement in $\mathrm{CH}_{3} \mathrm{CN}$ : The samples were prepared in an air-saturated $\mathrm{CH}_{3} \mathrm{CN}$ solution containing the complex with an absorbance of 0.1 at the irradiation wavelength, $\mathrm{N}, \mathrm{N}$ dimethyl-4-nitrosoaniline aniline (RNO, $24 \mu \mathrm{M})$ and imidazole $(12 \mathrm{mM})$. For the measurement in PBS buffer: The samples were prepared in an air-saturated PBS solution containing the complex with an absorbance of 0.1 at the irradiation wavelength, $\mathrm{N}, \mathrm{N}$-dimethyl-4-nitrosoaniline aniline (RNO, $20 \mu \mathrm{M})$ and histidine $(10 \mathrm{mM})$. The samples were irradiated on 96 well plates with an Atlas Photonics LUMOS BIO irradiator for different times. The absorbance of the samples was measured during these time intervals with an SpectraMax M2 Microplate Reader (Molecular Devices). The difference in absorbance $\left(A_{0}-A\right)$ at $420 \mathrm{~nm}$ for the $\mathrm{CH}_{3} \mathrm{CN}$ solution or at $440 \mathrm{~nm}$ a PBS buffer solution was calculated and plotted against the irradiation times. From the plot the slope of the linear regression was calculated as well as the absorbance correction factor determined. The singlet oxygen quantum yields were calculated using the same formulae as those used for the direct evaluation.

\section{Results and Discussion}

\subsection{Synthesis and characterisation of ruthenium-functionalized nanostructured materials}

The preparation of the ruthenium-functionalised materials MSN-CL-Ru, MSN-CNO-Ru and MSN-TRI-Ru was carried out using three different synthetic methods. For the preparation of MSN-CL-Ru the pathway A (Scheme 1) was followed. This consists of a simple grafting reaction of 3-chloropropyltriethoxysilane on dehydrated (treated for 24 hours at $150 \stackrel{\circ}{\circ}$ under vacuum) MSN to give MSN-CL following reported procedures. ${ }^{59,60}$ Subsequently, a functionalisation reaction with the ruthenium polypyridyl complex, $\left[\mathrm{Ru}(\mathrm{bipy})_{2}\right.$-dppz-7-hydroxymethyl] $\left[\mathrm{PF}_{6}\right]_{2}$, was carried out using a theoretical 5\% of Ru wt.\% (Ru/MSN). The reaction was performed in the presence of triethylamine (1.5 equivalent per equivalent of ruthenium) to promote the deprotonation of the alcohol group of the polypyridyl ruthenium compound and elimination of triethylammonium chloride to give the covalently supported ruthenium complex. 


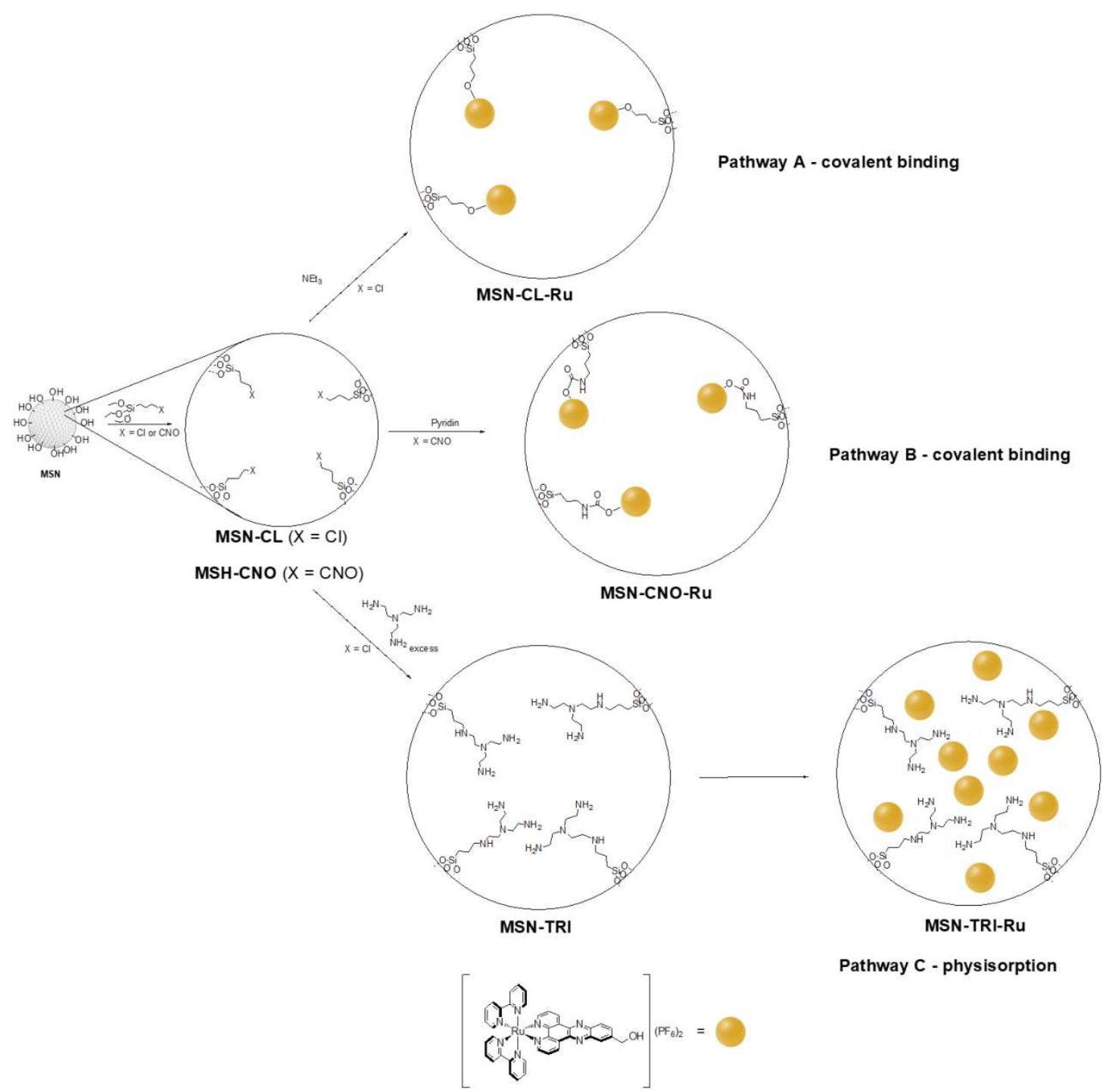

Scheme $1 . \%$ of Ru grafted on the mesoporous silica nanoparticles.

The theoretical amount of ruthenium in the reaction was adjusted according to a previous loading study that was carried out using different starting quantities of ruthenium $(2.5,5,10$ and $15 \%$ wt. Ru/MSN) which showed the best efficacy in functionalisation when using $5 \%$ wt. ruthenium (Table 1).

Table 1. \% of Ru grafted on the mesoporous silica nanoparticles.

$\begin{array}{cccc}\text { Material } & \text { Theoretical \%Ru wt. } & \begin{array}{c}\text { Experimental \%Ru } \\ \text { wt. }^{1}\end{array} & \begin{array}{c}\text { Experimental mmol } \\ \text { of Ru/g material }\end{array} \\ \text { MSN-CL-Ru } & 5 & 2.1 & 0.21 \\ \text { MSN-CNO-Ru } & 5 & 3.1 & 0.31 \\ \text { MSN-TRI-Ru } & 20 & 7.5 & 0.74 \\ & { }^{1} \text { Determined by X-ray fluorescence. } & \end{array}$

Analogously, for the preparation of MSN-CNO-Ru the pathway B (Scheme 1) was performed. This consists of the functionalisation of MSN with 3-isocyanatopropyltriethoxysilane 
to give MSN-CNO and the subsequent reaction with the ruthenium polypyridyl complex (using a theoretical $5 \%$ of Ru wt.\% Ru/MSN) in the presence of pyridine (1.5 equivalent per equivalent of ruthenium). This synthetic procedure led to the covalent functionalisation of the material with the ruthenium complex via the formation of the corresponding urethane derivative (Scheme 1, pathway B).

Finally, material MSN-CL was treated with tris(2-aminoethyl)amine giving rise to a polyamine-functionalized MSN (MSN-TRI) which was treated with an ethanolic suspension of the ruthenium polypyridyl complex (with a theoretical $20 \mathrm{wt} . \% \mathrm{Ru} / \mathrm{MSN}$ ) under reflux conditions for $48 \mathrm{~h}$ to obtain the ruthenium-physiosorbed material MSN-TRI-Ru (Scheme 1, Pathway C). The material was not washed to avoid the leaching of the adsorbed complex. In this case, an adsorption of the ruthenium derivative is presumably achieved via intermolecular interactions between the polar groups of ruthenium complex and the amino groups attached to the material, although electrostatic interactions between protonated amines of the material, the anionic $\mathrm{PF}_{6}{ }^{-}$ and the cationic ruthenium moiety cannot be ruled out.

\subsubsection{X-ray fluorescence}

The ruthenium-loaded materials MSN-CL-Ru, MSN-CNO-Ru and MSN-TRI-Ru were characterised by XRF observing a very different quantity of Ru wt. \%. For the covalent loaded ruthenium complexes MSN-CL-Ru and MSN-CNO-Ru only $2.1 \%$ and $3.1 \%$ of Ru was found, while in the case of the material with the physiosorbed Ru complex a much higher quantity of $7.5 \%$ wt. Ru was observed (Table 1). It is important to note that we tried some other synthetic approaches for increasing the quantity of loaded $\mathrm{Ru}$ by covalent modification or physical adsorption. However, we did not succeed in achieving this using other methods and different quantities of the ruthenium compound (See supplementary material). The observed low functionalisation using pathways $A$ and $B$ was attributed to the weak acidity of the alcoholic proton of the ruthenium complex and also to the partial saturation of the pores of the mesoporous silica nanoparticles with the different ligands (chloroproyltriethoxysilane or isocianatopropyltriethoxysilane in MSN-CL or MSN-CNO, respectively) which reduced the degree of Ru-functionalisation.

\subsubsection{Powder X-ray diffraction}

All the materials have been characterised by XRD. In all cases, the diffractograms show typical reflections for hexagonally ordered mesoporous materials, with relatively broad diffraction peaks. Non-modified MSN material gave a sharp peak at a $2 \theta$ value of ca. $2.1^{\circ}$ corresponding to the Miller plane (100), another two peaks of very low intensity were observed at ca. $3.8^{\circ}$ and $4.2^{\circ}$ which correspond with the (110) and (200) Miller planes, respectively. (Figure 1).

Interestingly, after the consecutive functionalization reactions with the different organic fragments and finally with the ruthenium photosensitiser, the position of the peaks slightly shifted to higher $2 \theta$ values and the intensity of the peaks notably decreased. The decrease in the intensity of the peaks is presumably due to the partial blocking of the dispersion points of the material while the slight shift towards higher diffraction angles confirm that the structural mesoporous order is retained after functionalisation reactions and that, apparently, the pore size notably decreases. 


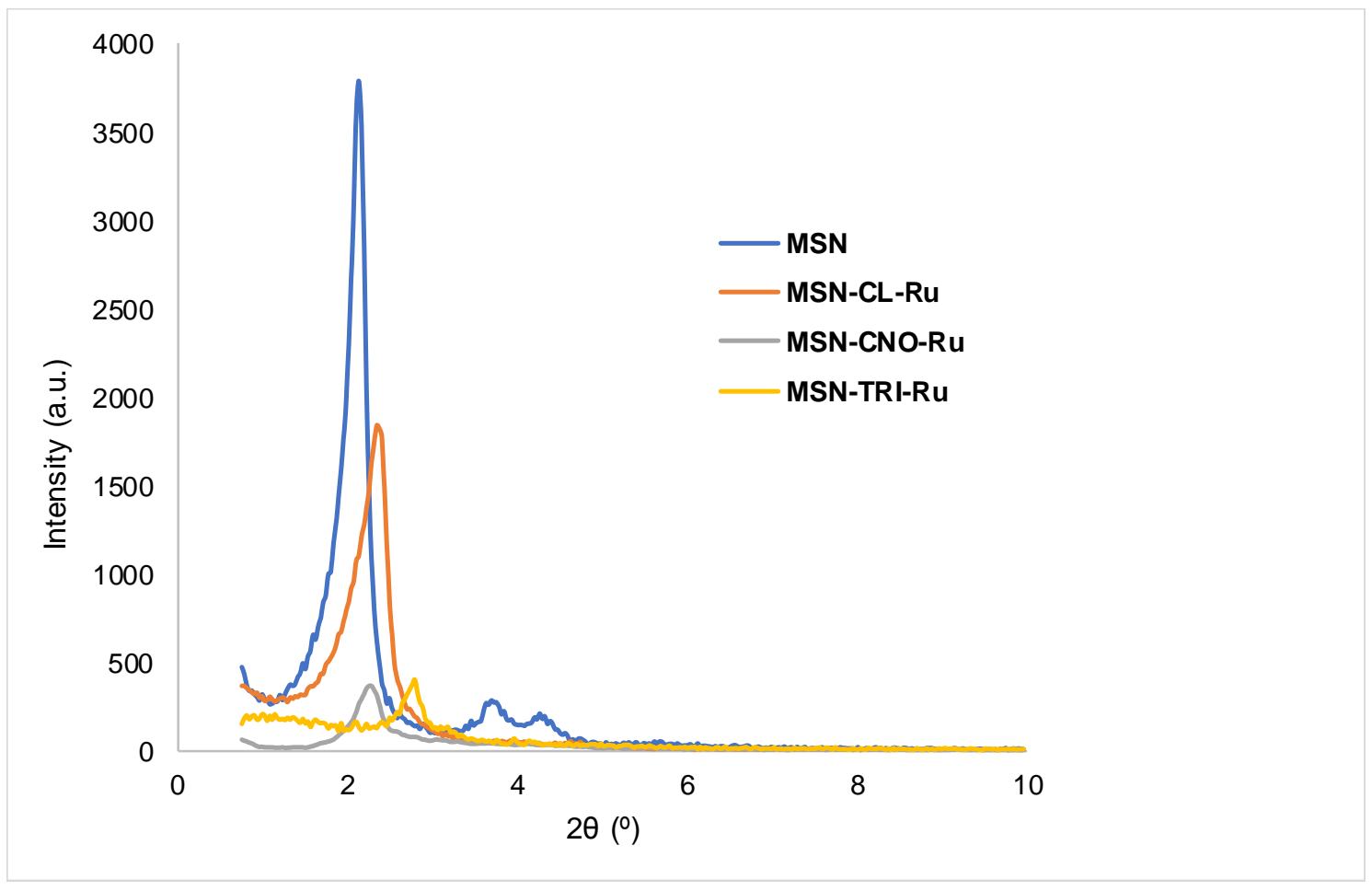

Figure 1. XRD Diffractograms of MSN, MSN-CL-Ru, MSN-CNO-Ru and MSN-TRI-Ru.

\subsection{3. $\mathrm{N}_{2}$ adsorption-desorption isotherms}

The unmodified MSN and the ruthenium-functionalised materials MSN-CL-Ru, MSN-CNORu and MSN-TRI-Ru have been characterised by nitrogen adsorption / desorption isotherms. In the cases of MSN, MSN-CL-Ru and MSN-CNO-Ru, the observed isotherms are between type IV and type VI (Figure 2) according to IUPAC classification. ${ }^{61}$ These isotherms are associated with mesoporous silica nanoparticles and show three different parts, namely, below $\mathrm{P} / \mathrm{P}_{0}$ ca. 0.4 , between $P / P_{0} 0.4$ and 0.9 and above $P / P_{0}$ 0.9. A hysteresis loop was observed in these cases between $P / P_{0} 1.0$ and 0.85 which is correlated with the existence of capillary condensation into the mesoporous structure of the porous system. Furthermore, an additional hysteresis loop was observed between $\mathrm{P} / \mathrm{P}_{0} 0.4$ and 0.15 .

On the other hand, the isotherm found for material MSN-TRI-Ru is a type III isotherm (Figure 2) with a hysteresis loop between $\mathrm{P} / \mathrm{P}_{0} 1.0$ and 0.85 which is indicative of a non-porous system as it corresponds after the physical adsorption of the ruthenium complex inside the pores.

Table 2. Physical parameters of MSN, MSN-CL-Ru, MSN-CNO-Ru and MSN-TRI-Ru measured by $\mathrm{N}_{2}$ adsorption-desorption isotherms

$\begin{array}{cccc}\text { Material } & \mathbf{S}_{\mathrm{BET}}\left(\mathrm{m}^{2} / \mathbf{g}\right) & \text { Total pore volume }\left(\mathrm{cm}^{3} / \mathbf{g}\right) & \mathbf{D}_{\mathrm{P}}(\mathrm{BJH})^{\mathbf{1}}(\mathbf{n m}) \\ \text { MSN } & 853 & 0.728 & 2.54 \\ \text { MSN-CL-Ru } & 717 & 0.563 & <2.0 \\ \text { MSN-CNO-Ru } & 295 & 0.299 & <2.0 \\ \text { MSN-TRI-Ru } & 7 & 0.022 & <2.0 \\ & & & \end{array}$


Table 2 gives all the physical parameters that show that starting MSN material has a very high $\mathrm{S}_{\mathrm{BET}}$ of $853 \mathrm{~m}^{2} \mathrm{~g}^{-1}$ and a BJH pore diameter of $2.5 \AA$. In addition, a very narrow distribution of the pore diameter was observed (see supplementary material). After functionalisation with the different ligands and ruthenium complex, the $S_{B E T}$ significantly decreased to 717 and $295 \mathrm{~m}^{2} \mathrm{~g}^{-1}$ for MSN-CL-Ru and MSN-CNO-Ru, respectively. This decrease indicates that the functionalisation takes place inside the pores of the mesoporous system. In the case of MSNTRI-Ru, the decrease in the BET surface is dramatic going down to $7 \mathrm{~m}^{2} \mathrm{~g}^{-1}$ owing to the complete blocking of the pores by the incorporation of both the tris-amino ligand and the ruthenium complex. A very high congestion of the pores is already observed after functionalization with the tris amine in MSN-TRI as the BET surface is already as low as $47 \mathrm{~m}^{2} \mathrm{~g}$. ${ }^{1}$ (Figure S8 and Table S1 of supplementary material) which is the main reason of the relatively low physisorption of the ruthenium compound. A similar behaviour has already been found for analogous systems in previous studies. ${ }^{59}$ Nevertheless, one cannot rule out that a plausible explanation of the very low surface area may also be an inhomogeneous functionalization.

It is important to note that, after the functionalisation with the different ligands and the ruthenium complex, the resulting materials gave pore size distributions with a maximum below $2.0 \mathrm{~nm}$, which is a significant decrease of more than $0.5 \mathrm{~nm}$ compared with the unmodified MSN, indicating, again, that the functionalisation may have been taken place inside the pores of the nanostructured system.

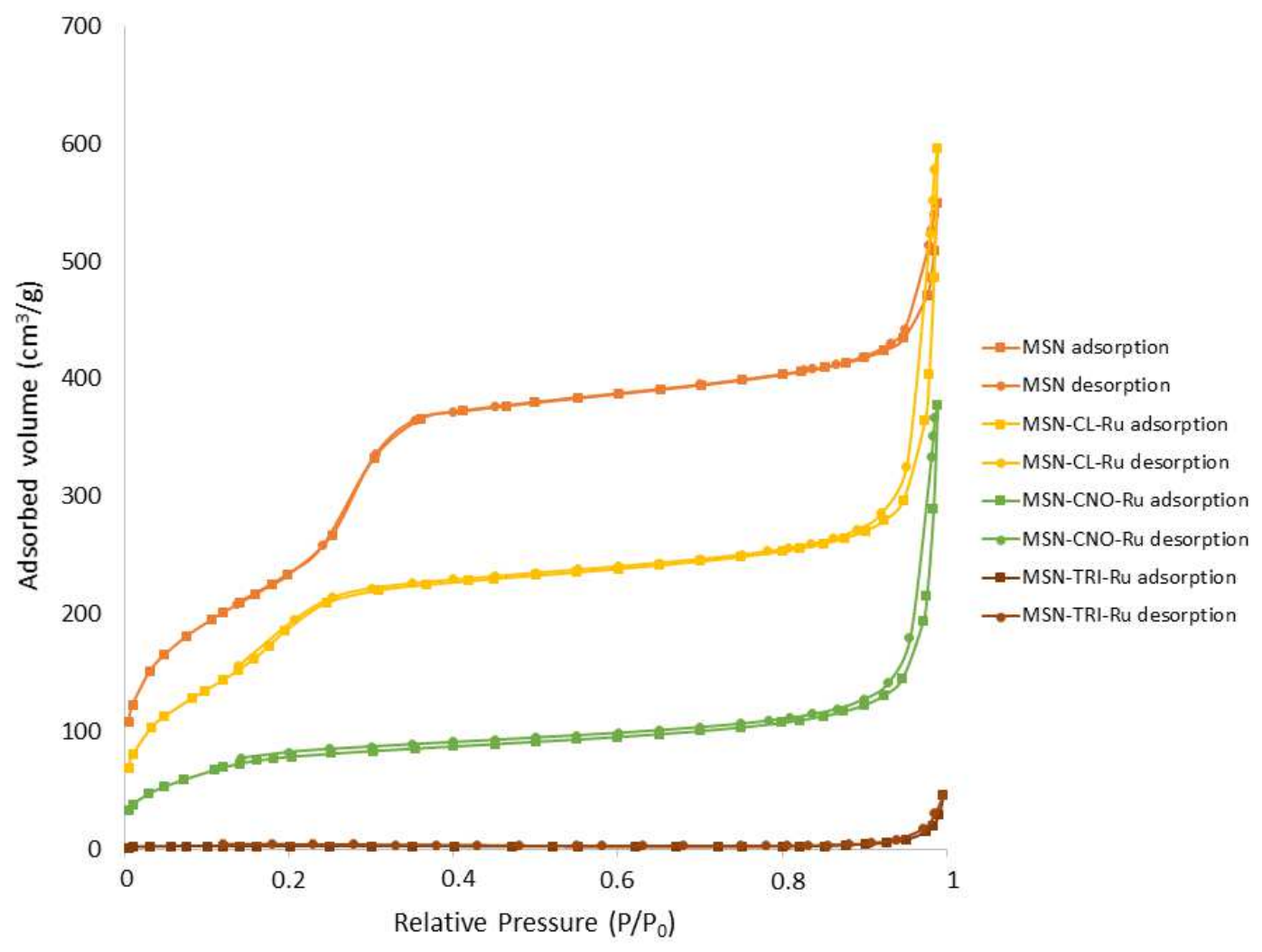

Figure 2. $\mathrm{N}_{2}$ adsorption / desorption isotherms of MSN, MSN-CL-Ru, MSN-CNO-Ru and MSN-TRI-Ru.

\subsubsection{Solid-state NMR spectroscopy}

The ${ }^{13} \mathrm{C}$ CP MAS spectra of materials MSN-CL-Ru, MSN-CNO-Ru and MSN-TRI-Ru. (Figure 3) have been recorded. The spectra show the signals associated with the different carbon atoms of the different ligands and the ruthenium complex that are attached to the mesoporous silica nanoparticles. In general, two different set of signals are found in each of the 
spectra of the different studied materials. One set of signals was recorded between ca. 0 and 60 $\mathrm{ppm}$ and was assigned to the aliphatic carbon atoms of the fragment coming from the 3chloropropyl moiety in MSN-CL-Ru, from the 3-isocyanatopropyl moiety in MSN-CNO-Ru or from the tris-amine in MSN-TRI-Ru. In addition, the aliphatic carbon atoms of the alcoholic fragment of the ruthenium complex are also part of that set of signals. The second set of signals appear between 110 and $170 \mathrm{ppm}$ and is assigned to the aromatic carbon atoms of the covalently bound (for MSN-CL-Ru, MSN-CNO-Ru) or physically adsorbed (in MSN-TRI-Ru) polypyridyl ruthenium complex in the different synthesised materials. It is important to note that the intensity of the signals of the carbon atoms of the ruthenium complex are not very high in the case of the materials MSN-CL-Ru and MSN-CNO-Ru (covalently bound) as it corresponds with a low ruthenium functionalisation rate. However, in the case of the material MSN-TRI-Ru, the relative intensity of the signals of the carbon atoms of the polypyridyl ligand of the ruthenium complex are much higher, as the quantity of immobilised complex is also much higher.
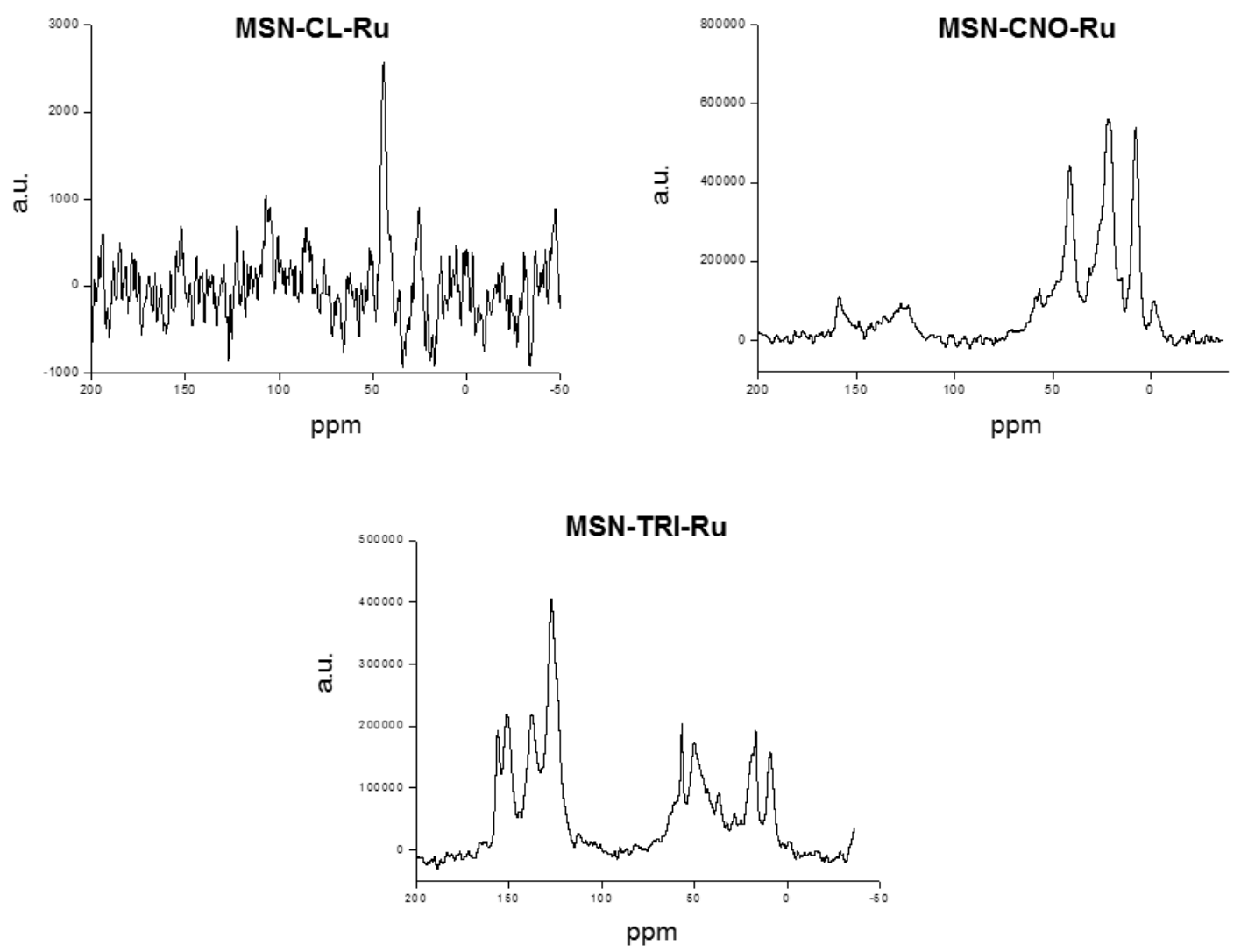

Figure $3 .{ }^{13} \mathrm{C}$ CP MAS NMR spectra of MSN-CL-Ru, MSN-CNO-Ru and MSN-TRI-Ru.

\subsubsection{IR and UV spectroscopy}

DR-UV-vis spectra of the studied ruthenium containing materials MSN-CL-Ru, MSN-CNORu and MSN-TRI-Ru were recorded. The spectra show a very intense absorption peak at 286 $\mathrm{nm}$ and a small shoulder of absorption at $443 \mathrm{~nm}$ which correspond with the incorporation of the ruthenium complex (see supplementary material). In addition, FT-IR spectra of the materials show the appearance of typical $\mathrm{C}-\mathrm{H}$ and $\mathrm{N}-\mathrm{H}$ small intensity bands due to the immobilisation of the ruthenium complex together with the typical characteristic bands of the silica intense broad bands between 3450 and $3200 \mathrm{~cm}^{-1}$, $(\mathrm{O}-\mathrm{H}$ stretching of the silanol groups of the material and the adsorbed water molecules), a broad band at around $1100 \mathrm{~cm}^{-1}$ (assigned to the siloxane (Si-O-Si) groups) and the stretching band of the $\mathrm{Si}-\mathrm{O}$ bonds at ca. $900 \mathrm{~cm}^{-1}$. Finally, a band at 
$1630 \mathrm{~cm}^{-1}$ was observed and corresponds with the deformation vibrations of adsorbed water molecules (see supplementary material).

\subsubsection{SEM and TEM}

The ruthenium-functionalised materials MSN-CL-Ru, MSN-CNO-Ru and MSN-TRI-Ru were characterised by Scanning Electronic Microscopy (SEM) and Transmission Electronic Microscopy (TEM) to observe their morphology, particle size and pore size.

In the SEM micrographs, one can see the agglomeration of the spherical nanoparticles (Figure 4). It seems that the functionalisation with the ruthenium complex, either by covalent binding or physical adsorption, do not lead to changes in the spherical morphology of the nanoparticles.
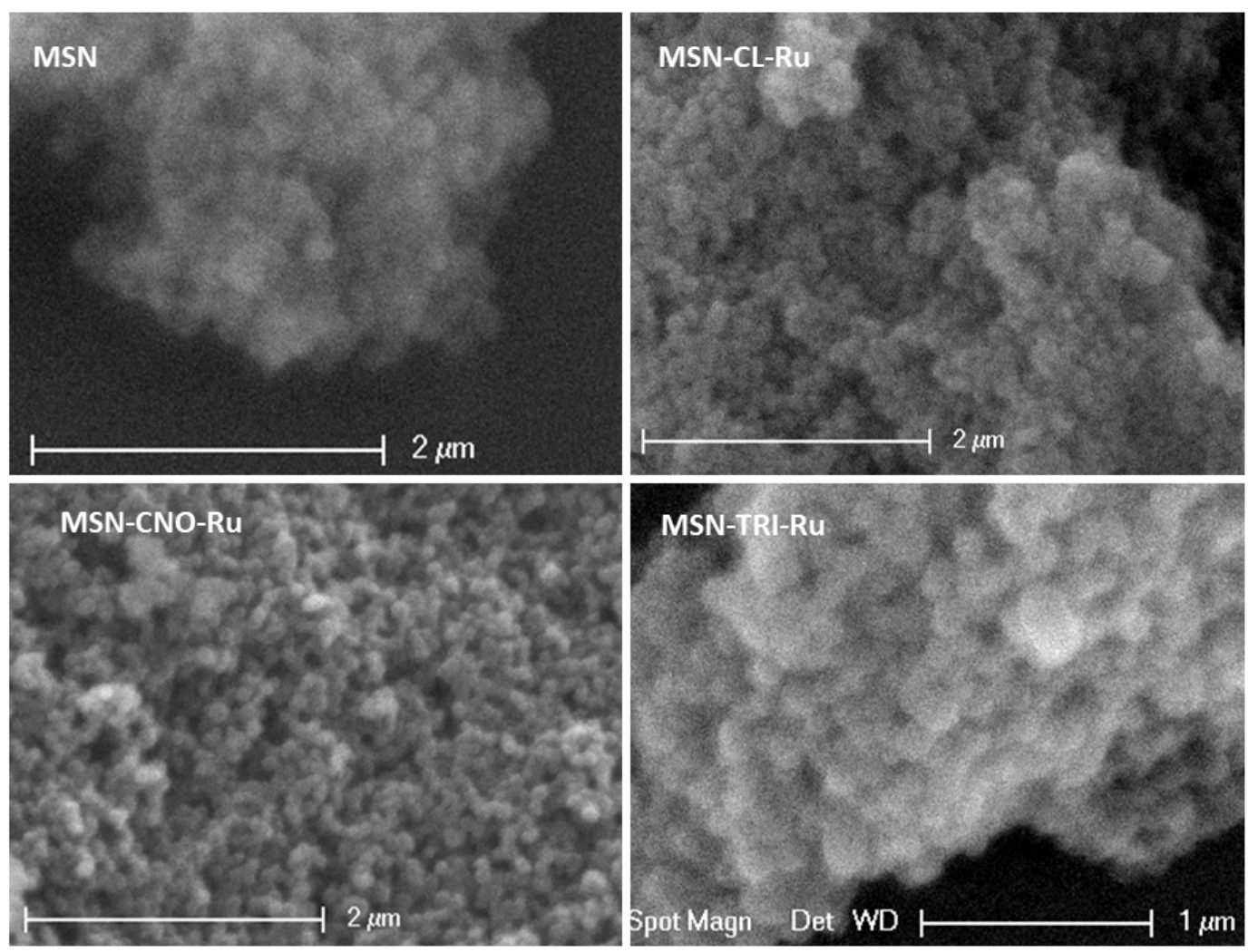

Figure 4. SEM images of MSN, MSN-CL-Ru, MSN-CNO-Ru and MSN-TRI-Ru.

TEM images of the ruthenium-functionalised nanomaterials MSN-CL-Ru, MSN-CNO-Ru and MSN-TRI-Ru (Figure 5) show the porous spheres with hexagonal ordered porous parallel channels. The particle size distribution calculated by using Image ${ }^{\circledR}$ program is very narrow and is of $77 \pm 13 \mathrm{~nm}$ for MSN-CL-Ru, $72 \pm 8 \mathrm{~nm}$ for MSN-CNO-Ru and $77 \pm 10 \mathrm{~nm}$ for MSN-TRI-Ru. The differences in size with the different functionalization are only probably due to a statistic factor. It seems, therefore, that the functionalisation with the ruthenium complex does not have any significant effect on the morphology or particle size of the materials. 


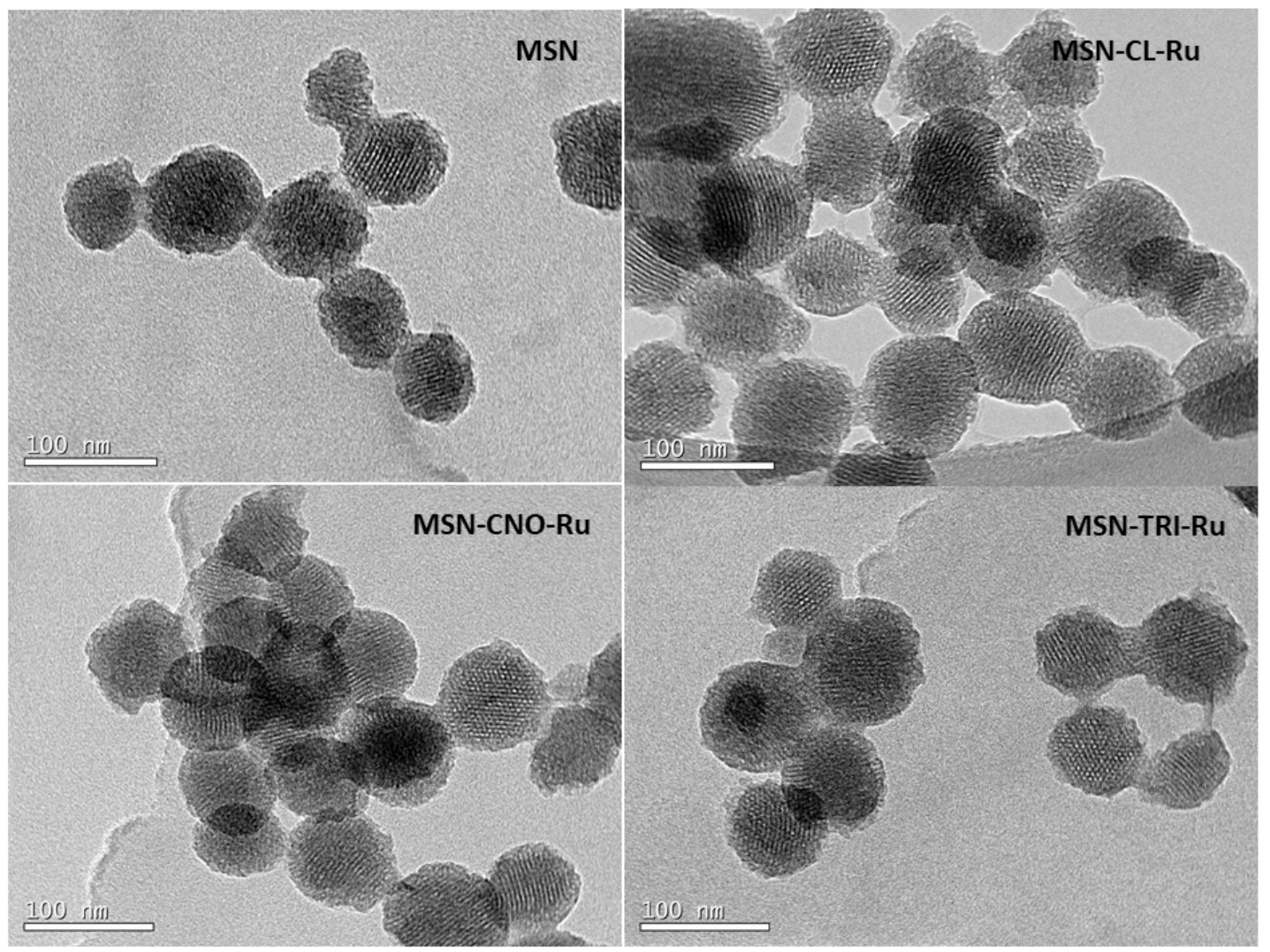

Figure 5. TEM images of MSN, MSN-CL-Ru, MSN-CNO-Ru and MSN-TRI-Ru.

\subsection{Biological studies}

The (photo-)toxic potential of the new MSNs conjugated to the ruthenium photosensitizer were evaluated on human cervical HeLa cancer cells. In this assay, we chose to investigate MSNCNO-Ru (3.1\% Ru loading) and MSN-TRI-Ru (7.5\% Ru loading), which have the highest Ru loading. The parent $\mathrm{Ru}(\mathrm{II})$ complex was also included as control in our experiments. Of note, for a fair comparison purpose, the concentrations are given as $\mu \mathrm{M}$ of the ruthenium complex in the materials. The results are summarised in Table 3 and representative dose-response plots are shown in Figure 6. The cells were treated with increasing concentrations of materials and incubated for $4 \mathrm{~h}$ and $48 \mathrm{~h}$ to test cytotoxicity in the dark. As shown in Table 3, very low toxicity $\left(\mathrm{IC}_{50}\right.$ values $183-278 \mu \mathrm{M}$, Table 3) was noticed for both MSNs and the parent $\mathrm{Ru}(\mathrm{II})$ complex. In the $4 \mathrm{~h}$ incubation assay in the dark, only MSN-TRI-Ru showed some toxicity with an $\mathrm{IC}_{50}$ value of $252 \mu \mathrm{M}$. The parent Ru(II) complex and MSN-CNO-Ru turned out to be non-toxic up to a 400 $\mu \mathrm{M}$ concentration. These results are in line with our expectations considering that MSN-TRI-Ru has the highest Ru loading of the material series. Unfortunately, as shown in Table 3, no significant differences in the $\mathrm{IC}_{50}$ values were observed when cells treated with our compounds were irradiated with $350 \mathrm{~nm}$ light for $10 \mathrm{~min}\left(2.58 \mathrm{Jcm}^{-2}\right)$. We note that this light dose is not toxic for cells.

In order to rationalise the modest results obtained when using $350 \mathrm{~nm}$ light, two hypothesises can be envisioned, namely 1) a quenching of the $R u(I I)$ complex due to a possible surface quenching or 2) a too low Ru loading. Regarding 2), our efforts to quantify the uptake of these compounds using either ICP-MS or fluorescence microscopy was fruitless due to precipitation of the ruthenium-containing MSNs in cell culture media. For 1), we have carried out emission, luminescence, lifetimes and ${ }^{1} \mathrm{O}_{2}$ quantum yields measurements on the most active material, namely MSN-TRI-Ru (see section 3.3). 
Table 3. (Photo-)toxicity of MSNs and parent Ru(II) complex in HeLa cells given in $\mu \mathrm{M}$ of ruthenium complex for Ru-complex or $\mu \mathrm{M}$ of loaded ruthenium complex for materials MSNCNO-Ru and MSN-TRI-Ru. Data in brackets correspond with the quantity of functionalised materials MSN-CNO-Ru and MSN-TRI-Ru in $\mu \mathrm{g} / \mathrm{mL}$.

\begin{tabular}{|c|c|c|c|}
\hline Compounds & $48 \mathrm{~h} /$ dark & $4 \mathrm{~h} /$ dark & $\begin{array}{c}4 \mathrm{~h} / 350 \mathrm{~nm} \text { light, } \\
10 \mathrm{~min}\left(2.58 \mathrm{Jcm}^{-2}\right)\end{array}$ \\
\hline MSN-CNO-Ru & $\begin{array}{c}278 \pm 14 \\
{[903 \pm 40]}\end{array}$ & $\begin{array}{c}>400 \\
{[>1300]}\end{array}$ & $\begin{array}{c}>400 \\
{[>1300]}\end{array}$ \\
\hline MSN-TRI-Ru & $\begin{array}{c}219 \pm 21 \\
{[295 \pm 26]}\end{array}$ & $\begin{array}{c}252 \pm 16 \\
{[340 \pm 19]}\end{array}$ & $\begin{array}{c}216 \pm 18 \\
{[291 \pm 22]}\end{array}$ \\
\hline Ru-complex & $183 \pm 19$ & $>400$ & $329 \pm 21$ \\
\hline
\end{tabular}
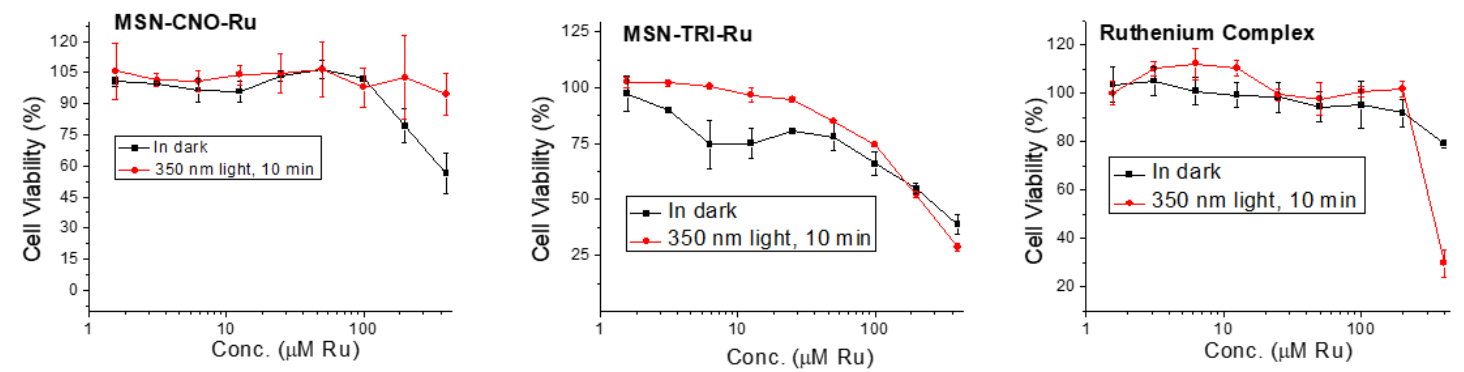

Figure 6. Representative dose-response curves of the phototoxicity assays with MSNs and parent Ru complex in Hela cells. Note: Concentrations are given as $\mu \mathrm{M}$ of the ruthenium complex in the materials.

\subsection{Photophysical Studies}

\subsubsection{Emission, Luminescence and Lifetimes}

The low biological activity observed in section 3.2 could be potentially explained by a quenching of the excited state of the Ru(II) complex in the nanoparticle. In order to exclude this possibility, emission, luminescence and lifetimes measurements were undertaken on the most active nanoparticles (MSN-TRI-Ru) and compared to the Ru(II) complex itself. The values of MSNTRI-Ru and the $R \mathbf{u}(\mathrm{II})$ complex presented in Table 4 are very similar and seem to rule out any quenching of the excited state of the $\mathrm{Ru}$ (II) complex.

Table 4. Spectroscopic properties of $\mathbf{M S N}-\mathrm{TRI}-\mathrm{Ru}$ in $\mathrm{CH}_{3} \mathrm{CN}$ at room temperature.

\begin{tabular}{|c|c|c|c|c|}
\hline Compound & Emission $\lambda_{\mathrm{em}} / \mathrm{nm}$ & $\Phi_{\mathrm{em}} / \%$ & \multicolumn{2}{|c|}{ Lifetime $/ \mathrm{ns}$} \\
\hline & & & air & degassed \\
\hline MSN-TRI-Ru & 622 & 1.9 & 205 & 952 \\
\hline Ru-complex & 623 & 3.1 & 186 & 914 \\
\hline
\end{tabular}




\subsubsection{Singlet oxygen production}

To further explore a potential quenching of the excited state of the $\mathrm{Ru}$ (II) complex, the singlet oxygen quantum yields of MSN-TRI-Ru were determined by direct and indirect methods, as previously described by some of us. ${ }^{35,51,53,56}$ The values presented in Table 5 are in the same order of magnitude and seem to exclude a quenching of the excited state. Overall, the results presented in this section tend to confirm that the low Ru loading is responsible for the modest biological activity observed.

Table 5. ${ }^{1} \mathrm{O}_{2}$ quantum yields $\left(\Phi\left({ }^{1} \mathrm{O}_{2}\right)\right)$ in air saturated $\mathrm{CH}_{3} \mathrm{CN}$ and aqueous solution determined by direct and indirect method upon excitation at $450 \mathrm{~nm}$. Average of three independent measurements, $+-10 \%$. n.d. $=$ not detectable ${ }^{*}=$ containing $5 \%$ DMSO.

\begin{tabular}{|c|c|c|c|c|}
\hline Compound & $\begin{array}{c}\mathrm{CH}_{3} \mathrm{CN} \\
\text { direct }\end{array}$ & $\begin{array}{c}\mathrm{CH}_{3} \mathrm{CN} \\
\text { indirect }\end{array}$ & $\begin{array}{c}\mathrm{D}_{2} \mathrm{O}^{*} \\
\text { direct }\end{array}$ & $\begin{array}{c}\text { PBS }^{*} \\
\text { indirect }\end{array}$ \\
\hline MSN-TRI-Ru & 62 & 59 & n.d. & $1 \%$ \\
\hline Ru-complex & 92 & 94 & n.d. & $3 \%$ \\
\hline
\end{tabular}

\section{Conclusions}

We have synthesised and characterised by different methods various mesoporous silica nanoparticles functionalised with the photoactive ruthenium(II) complex $R u(b i p y)_{2}$-dppz-7hydroxymethyl] $\left[\mathrm{PF}_{6}\right]_{2}$. We have observed that the covalent binding of the ruthenium complex can be achieved with modest functionalisation rates (between ca. 2-3\% wt. Ru) by its reaction with chloropropyl- or isocyanatopropyl-functionalised nanoparticles via ether or urethane formation with the addition of different bases. In addition, physical adsorption of the ruthenium(II) complex leads to higher functionalisation rates of ca. $7 \%$ when using polyamine ligands attached to the mesoporous silica nanoparticles. The preliminary biological results on HeLa cervical cancer cells showed that the low loading of ruthenium complexes hampered phototoxicity. Future work will be in the preparation of higher-loader material.

Supplementary Materials: The supplementary material contains the main scheme of the reactions carried out in this study; experimental description of additional reactions for incorporation of ruthenium complex with low functionalization rates; pore size distribution of the studied materials; DR-UV spectra of the studied materials, FT-IR spectra of the studied materials, MSN and ruthenium complex, nitrogen adsorption-desorption isotherm of MSN-TRI and table with the comparison of physical parameters of MSN, MSN-TRI, MSN-TRI-Ru measured by $\mathrm{N}_{2}$ adsorption-desorption isotherm and emission and lifetime spectra of MSN-TRI-Ru.

Acknowledgments: We gratefully acknowledge financial support from the former Ministerio de Economía y Competitividad-FEDER (current Ministerio de Ciencia, Innovación y Universidades) Spain (Grant no. CTQ2015-66164-R and CTQ2017-90802-REDT), the Swiss National Science Foundation (Professorships No. PP00P2_133568 and PP00P2_157545 to G.G), the University of Zurich (G.G) and the ERC (Consolidator Grant PhotoMedMet ( $\bar{G} A$ 681679) to G.G.). We would also like to thank Universidad Rey Juan Carlos and Banco de Santander for supporting our Research Group of Excellence QUINANOAP (S.G.). This work has received support under the program «Investissements d'Avenir » launched by the French Government and implemented by the ANR with the reference ANR-10-IDEX-0001-02 PSL (G.G.). We thank Dr. Philippe Goldner for access to a state-of-the-art photophysical apparatus.

Ethical statement: Not applicable.

Conflicts of Interest: The authors declare no conflict of interest.

\section{References}

1 B. Rosenberg and L. VanCamp, Cancer Res., 1970, 30, 1799-1802. 
2 K. D. Mjos and C. Orvig, Chem. Rev., 2014, 114, 4540-4563.

3 U. Ndagi, N. Mhlongo and M. E. Soliman, Drug Des. Devel. Ther., 2017, 11, 599-616.

4 L. Astolfi, S. Ghiselli, V. Guaran, M. Chicca, E. Simoni, E. Olivetto, G. Lelli and A. Martini, Oncol. Rep., 2013, 29, 1285-1292.

5 M. Wenzel and A. Casini, Coord. Chem. Rev., 2017, 352, 432-460.

6 S. Spreckelmeyer, C. Orvig and A. Casini, Molecules, 2014, 19, 15584-15610.

7 G. Housman, S. Byler, S. Heerboth, K. Lapinska, M. Longacre, N. Snyder and S. Sarkar, Cancers, 2014, 6, 1769-1792.

8 X. Dong and R. J. Mumper, Nanomedicine, 2010, 5, 597-615.

9 T. Kiss, É. A. Enyedy and T. Jakusch, Coord. Chem. Rev., 2017, 352, 401-423.

10 W. Wani, S. Shreaz, S. Prashar and S. Gómez-Ruiz, Coord. Chem. Rev., 2016, 312, 6798

11 Y. Ellahioui, S. Prashar and S. Gómez-Ruiz, Curr. Med. Chem., 2016, 23, 4450-4467.

12 D. Pérez-Quintanilla, S. Gómez-Ruiz, Ž. Žižak, I. Sierra, S. Prashar, I. del Hierro, M. Fajardo, Z. D. Juranić and G. N. Kaluđerović, Chem. Eur. J., 2009, 15, 5588-5597.

13 G. N. Kaluđerović, D. Pérez-Quintanilla, I. Sierra, S. Prashar, I. del Hierro, Ž. Žižak, Z. D. Juranić, M. Fajardo and S. Gómez-Ruiz, J. Mater. Chem., 2010, 20, 806-814.

14 G. N. Kaluderović, D. Pérez-Quintanilla, Z. Zizak, Z. D. Juranić and S. Gómez-Ruiz, Dalton Trans, 2010, 39, 2597-2608.

15 A. García-Peñas, S. Gómez-Ruiz, D. Pérez-Quintanilla, R. Paschke, I. Sierra, S. Prashar, I. del Hierro and G. N. Kaluđerović, J. Inorg. Biochem., 2012, 106, 100-110.

16 J. Ceballos-Torres, P. Virag, M. Cenariu, S. Prashar, M. Fajardo, E. Fischer-Fodor and S. Gómez-Ruiz, Chem. Eur. J., 2014, 20, 10811-10828.

17 J. Ceballos-Torres, S. Prashar, M. Fajardo, A. Chicca, J. Gertsch, A. B. Pinar and S. Gómez-Ruiz, Organometallics, 2015, 34, 2522-2532.

18 S. Gómez-Ruiz, A. García-Peñas, S. Prashar, A. Rodríguez-Diéguez and E. Fischer-Fodor, Materials, 2018, 11, 2.

19 I. del Hierro, S. Gómez-Ruiz, Y. Pérez, P. Cruz, S. Prashar and M. Fajardo, Dalton Trans. 2018, in press, DOI: 10.1039/C8DT02011F

20 D. Díaz-García, D. Cenariu, Y. Pérez, P. Cruz, I. del Hierro, S. Prashar, E. Fischer-Fodor and S. Gómez-Ruiz, Dalton Trans. 2018, in press, DOI: 10.1039/C8DT01677A

21 M. Z. Bulatović, D. Maksimović-Ivanić, C. Bensing, S. Gómez-Ruiz, D. Steinborn, H. Schmidt, M. Mojić, A. Korać, I. Golić, D. Pérez-Quintanilla, M. Momčilović, S. Mijatović and G. N. Kaluđerović, Angew. Chem. Int. Ed. Engl., 2014, 53, 5982-5987.

22 C. Bensing, M. Mojić, S. Gómez-Ruiz, S. Carralero, B. Dojčinović, D. Maksimović-Ivanić, S. Mijatović and G. N. Kaluđerović, Dalton Trans, 2016, 45, 18984-18993.

23 M. Appold, C. Mari, C. Lederle, J. Elbert, C. Schmidt, I. Ott, B. Stühn, G. Gasser and M. Gallei, Polym. Chem., 2017, 8, 890-900.

24 C. Mari, V. Pierroz, S. Ferrari and G. Gasser, Chem. Sci., 2015, 6, 2660-2686.

25 L. Zeng, P. Gupta, Y. Chen, E. Wang, L. Ji, H. Chao and Z.-S. Chen, Chem. Soc. Rev., 2017, 46, 5771-5804.

26 F. Heinemann, J. Karges and G. Gasser, Acc. Chem. Res., 2017, 50, 2727-2736.

27 G. Shi, S. Monro, R. Hennigar, J. Colpitts, J. Fong, K. Kasimova, H. Yin, R. DeCoste, C. Spencer, L. Chamberlain, A. Mandel, L. Lilge and S. A. McFarland, Coord. Chem. Rev., 2015, 282-283, 127-138.

28 J. D. Knoll and C. Turro, Coord. Chem. Rev., 2015, 282-283, 110-126.

29 C. Mari and G. Gasser, Chimia, 2015, 69, 176-181.

30 B. A. Albani, B. Peña, N. A. Leed, N. A. B. G. de Paula, C. Pavani, M. S. Baptista, K. R. Dunbar and C. Turro, J. Am. Chem. Soc., 2014, 136, 17095-17101.

31 M. A. Sgambellone, A. David, R. N. Garner, K. R. Dunbar and C. Turro, J. Am. Chem. Soc., 2013, 135, 11274-11282.

32 R. B. Sears, L. E. Joyce, M. Ojaimi, J. C. Gallucci, R. P. Thummel and C. Turro, J. Inorg. Biochem., 2013, 121, 77-87.

33 L. N. Lameijer, D. Ernst, S. L. Hopkins, M. S. Meijer, S. H. C. Askes, S. E. Le Dévédec and S. Bonnet, Angew. Chem. Int. Ed. Engl., 2017, 56, 11549-11553.

34 A. Frei, R. Rubbiani, S. Tubafard, O. Blacque, P. Anstaett, A. Felgenträger, T. Maisch, L. Spiccia and G. Gasser, J. Med. Chem., 2014, 57, 7280-7292. 
35 C. Mari, V. Pierroz, R. Rubbiani, M. Patra, J. Hess, B. Spingler, L. Oehninger, J. Schur, I. Ott, L. Salassa, S. Ferrari and G. Gasser, Chem. Eur. J., 2014, 20, 14421-14436.

36 H. Huang, B. Yu, P. Zhang, J. Huang, Y. Chen, G. Gasser, L. Ji and H. Chao, Angew. Chem. Int. Ed. Engl., 2015, 54, 14049-14052.

37 S. Chakrabortty, B. K. Agrawalla, A. Stumper, N. M. Vegi, S. Fischer, C. Reichardt, M. Kögler, B. Dietzek, M. Feuring-Buske, C. Buske, S. Rau and T. Weil, J. Am. Chem. Soc., 2017, 139, 2512-2519.

38 R. Lincoln, L. Kohler, S. Monro, H. Yin, M. Stephenson, R. Zong, A. Chouai, C. Dorsey, R. Hennigar, R. P. Thummel and S. A. McFarland, J. Am. Chem. Soc., 2013, 135, 1716117175.

39 P. Kaspler, S. Lazic, S. Forward, Y. Arenas, A. Mandel and L. Lilge, Photochem. Photobiol. Sci., 2016, 15, 481-495.

40 C. S. Burke, A. Byrne and T. E. Keyes, J. Am. Chem. Soc., 2018, 140, 6945-6955.

41 Health Canada Approves Clinical Trial Application for Anti-Cancer Drug, http://theralase.com/pressrelease/health-canada-approves-clinical-trial-application-anticancer-drug/, (accessed June 4, 2018).

42 S. Rojas, F. J. Carmona, E. Barea and C. R. Maldonado, J. Inorg. Biochem., 2017, 166, 87-93.

43 D. Edeler, S. Arlt, V. Petković, G. Ludwig, D. Drača, D. Maksimović-Ivanić, S. Mijatović and G. N. Kaluđerović, J. Inorg. Biochem., 2018, 180, 155-162.

44 L. He, Y. Huang, H. Zhu, G. Pang, W. Zheng, Y.-S. Wong and T. Chen, Adv. Funct. Mater., 2014, 24, 2754-2763.

45 D. Zhang, Z. Wu, J. Xu, J. Liang, J. Li and W. Yang, Langmuir, 2010, 26, 6657-6662.

46 J. Wen, H. Yan, P. Xia, Y. Xu, H. Li and S. Sun, Sci. China Chem., 2017, 60, 799-805.

47 M. Frasconi, Z. Liu, J. Lei, Y. Wu, E. Strekalova, D. Malin, M. W. Ambrogio, X. Chen, Y. Y. Botros, V. L. Cryns, J.-P. Sauvage and J. F. Stoddart, J. Am. Chem. Soc., 2013, 135, 11603-11613.

48 S. Lechevallier, R. Mauricot, H. Gros-Dagnac, S. Chevreux, G. Lemercier, E. Phonesouk, M. Golzio and M. Verelst, ChemPlusChem, 2017, 82, 770-777.

49 N. Ž. Knežević, V. Stojanovic, A. Chaix, E. Bouffard, K. E. Cheikh, A. Morère, M. Maynadier, G. Lemercier, M. Garcia, M. Gary-Bobo, J.-O. Durand and F. Cunin, J. Mater. Chem. B, 2016, 4, 1337-1342.

50 R. Chouikrat, A. Seve, R. Vanderesse, H. Benachour, M. Barberi-Heyob, S. Richeter, L. Raehm, J.-O. Durand, M. Verelst and C. Frochot, Curr. Med. Chem., 2012, 19, 781-792.

51 J. Hess, H. Huang, A. Kaiser, V. Pierroz, O. Blacque, H. Chao and G. Gasser, Chem. Eur. J., 2017, 23, 9888-9896.

52 C. Mari, H. Huang, R. Rubbiani, M. Schulze, F. Würthner, H. Chao and G. Gasser, Eur. J. Inorg. Chem., 2017, 2017, 1745-1752.

53 C. Mari, R. Rubbiani and G. Gasser, Inorg. Chim. Acta, 2017, 454, 21-26.

54 Y. Zhao, B. G. Trewyn, I. I. Slowing and V. S.-Y. Lin, J. Am. Chem. Soc., 2009, 131, 83988400.

55 K. Nakamaru, Bull. Chem. Soc. Japan 1982, 55, 1639-1640.

56 C. Mari, V. Pierroz, A. Leonidova, S. Ferrari and G. Gasser, Eur. J. Inorg. Chem. 2015, 3879-3891.

57 I. E. Kochevar and R. W. Redmond, Methods in Enzymology, 2000, 319, 20-28.

58 D. García-Fresnadillo, Y. Georgiadou, G. Orellana, A. M. Braun and E. Oliveros, Helv. Chim. Acta 1996, 79, 1222-1238.

59 V. S. Bollu, A. K. Barui, S. K. Mondal, S. Prashar, M. Fajardo, D. Briones, A. RodríguezDiéguez, C. R. Patra and S. Gómez-Ruiz, Mater. Sci. Eng. C Mater. Biol. Appl., 2016, 63, 393-410.

60 S. Sánchez-Muñoz, S. Gómez-Ruiz, D. Pérez-Quintanilla, S. Morante-Zarcero, I. Sierra, S. Prashar, R. Paschke and G. N. Kaluđerović, ChemMedChem, 2012, 7, 670-679.

61 M. Thommes, K. Kaneko, A. V. Neimark, J. P. Olivier, F. Rodríguez-Reinoso and J. Rouquerol, Pure Appl. Chem., 2015, 87, 1051-1069. 